\title{
From the patient's side. On life, death, and taxes: reflections on cancer and kidney transplantation
}

\author{
Danielle L. Horton ${ }^{1}$
}

Published online: 4 August 2020

(C) Italian Society of Nephrology 2020

These are my reflections on two papers regarding the risk of getting cancer from a transplant and the risk of dying from a cancer in older people versus younger people after transplant, that I have been asked to read and comment $[1,2]$.

Being diagnosed with kidney failure at the age of 21 really forces you to grow up and realise that you are not invincible. All of a sudden you are no longer deciding what pub you are going to catch up with your friends at on the weekend but trying to work out what you are going to leave them to remember you by. It's quite a morbid thing dealing with your own mortality but when it's placed in front of you abruptly you soon learn what is important in life.

Six months of peritoneal dialysis and my kidneys switched back on. All of a sudden, the risk of dying disappeared and life continued on as before, going back to a normal life.

At 21 you don't think you need to be thinking about whether you can have children and have a family of your own, but throw in kidney failure and it almost seems impossible. After getting married and a lot of discussions about starting a family, the risks involved, with a lot of determination, great doctors, 2 weeks of dialysis and a lot of good luck, at age 28 I was blessed with a tiny daughter at 25 weeks gestation weighing $610 \mathrm{~g}(1 \mathrm{lb}, 5.5 \mathrm{ozs})$. The risk of death for both myself and my baby played a huge part of the fear I felt, but it gave me the drive and determination to go ahead with the decision.

Luckily for me, my kidneys switched back on and life went back to normal.

Editor's note: interpreting the fears and the risks is difficult on both the physicians' and the patients' side, and the views may be discordant. With this optic we invited an editorial from the patient's side, and we are glad to share this bright view from Australia.

Danielle L. Horton

georgina.irish@sa.gov.au

1 Mt Gambier, South Australia
Here we are 16 years on from my original diagnosis of kidney failure, 9 years after having a baby, I am still earth side. During this time I have had many ups and downs in my health with quite a few hurdles to get over. The fear of dying always playing a small part in the back of my mind, always playing it down as I feel it's easier for me to deal with than share my fears with my family and friends.

What do they say, there are two things that are certain in life and that's Death and Taxes. You know one day that your life will end, but you certainly hope that it is a long way into your future. Reading these two papers really hasn't changed my perspective on life and death, risks of getting cancer and dying from the cancer. I' $m$ not scared of dying, it's what I'm going to miss out on is what scares me the most.

The benefits that we get in receiving a life saving transplant far outweighs the risk of getting cancer from the transplant. There are so many things that could go wrong after transplant, like rejection or failure or even death on the operating table. There is risk with everything we do in life, but it's determining whether you do something and whether it's worth the risk. In this case a transplant is definitely worth the risk.

My life at the moment is quite busy. Working nine to three 5 days a week, doing dialysis four times a day 7 days a week, housework, cooking, cleaning, being a mum, a wife, a daughter and time out for myself, my days are very full.

Receiving a transplant is going to free up my days, it's going to make me feel better and live better. I'll will be able to do all the things in life that I am unable to do, like playing with my daughter, being able to feel attractive again for my husband without trying to hide my Tenckhoff catheter, to be able to love without being self conscious.

The biggest things I look forward to is going swimming at the pool or mucking around at the beach in the ocean, and the thing I miss the most and took for granted before I went back onto dialysis, is long soaks in a hot bubble bath. This is my go to when I am stressed and need to unwind, unfortunately I am unable to do this with my Tenckhoff catheter 


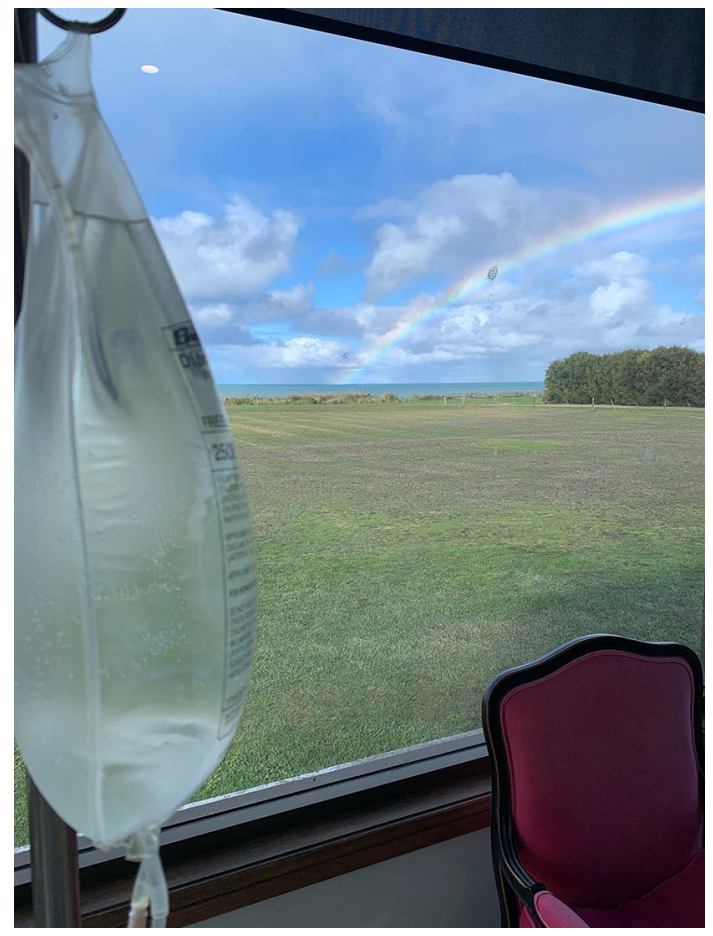

"Peritoneal Dialysis with a view". The sea and rainbow at Port MacDonnell in South Australia

and will be one of the first things I do once I am able to following my transplant.

The risk of getting cancer following transplant is a risk I know that I am willing to take. It's just another hurdle that I will jump if and when the time arrives. I am just as likely to get hit by a bus crossing the road and if I worried about that I would never leave the house. I know that there is a risk of dying from cancer from the transplant, but I will tend to ignore it and concentrate on the positive things I will get from the transplant, the main thing being an extended life.
I feel that I am lucky that I am young and have kidney failure, mainly due to the fact that I can still work and get about nice and easy, being older it would be a lot more difficult managing the condition. The fact that younger people are more likely to die from cancer than older people shows that kidney failure is much more taxing on older bodies.

Hopefully with all the testing that is available nowadays and into the future, we will hopefully be able to one day eliminate this risk from transplants.

\section{Compliance with ethical standards}

Conflict of interest The authors declare that they have no conflict of interest.

Ethical approval This article does not contain any studies with human participants or animals performed by any of the authors.

Informed consent For this type of study, formal consent is not required.

\section{References}

1. Eccher A, Girolami I, Motter JD, Marletta S, Zaza G, Gambaro G et al (2020) Donor-transmitted cancer in kidney transplant recipients: a systematic review. J Nephrol. https://doi.org/10.1007/s4062 0-020-00775-4

2. Tessari G, Maggiore U, Zaza G, Momo REN, Nacchia F, Boschiero $L$ et al (2020) Mortality from cancer is not increased in elderly kidney transplant recipients compared to the general population. A competing risk analysis. J Nephrol (this issue)

Publisher's Note Springer Nature remains neutral with regard to jurisdictional claims in published maps and institutional affiliations. 